\title{
THE APPEAL-TO-NATURE FALLACY HOMEOPATHY AND BIODYNAMIC AGRICULTURE IN OFFICIAL EU REGULATIONS
}

\author{
José Miguel Mulet
}

There is no scientific evidence to support the affirmation that organic food is more nutritious or that its production is more sustainable than traditional food. In addition, productivity is very low and, concomitantly, the price is higher. This article reviews the basics of EU regulations on organic food production and concludes that, for the most part, they mislead the consumer and are not science based. Most of them rely on concepts related to the appeal-to-nature fallacy, with the explicit presence of pseudosciences, such as homeopathy or biodynamic agriculture. On the other hand, interesting aspects such as the carbon footprint or local production are not present in the regulations, and technological improvements that could be useful for organic food production are excluded.

Keywords: EU organic food, appeal to nature, homeopathy, biodynamic agriculture, pseudoscience.

\section{WHAT IS ORGANIC FOOD?}

For the average consumer, the term organic food represents a sign of quality and added value. People associate the word organic with food produced without chemicals or pesticides, which is healthier, and environmentally friendly. Technically the terms organic, bio, or ecological define food that has been produced according to the organic regulations of the country or region, when the official administration has certified this fact and allows the use of the denomination and the official logo. A recent survey among 455 Spanish consumers of organic food concluded that the main reasons for buying organic were health benefits, avoidance of pesticide residue, and environmental benefits (GfK Emer Ad Hoc Research, 2011). The fact is that none of these assumptions that organic consumers believe are supported by scientific evidence. Several studies have shown that nutritional quality is similar in conventional and organic food. A recent study by Barańsky et al. (2014) indicated that the nutritional value of organic food could be higher thanks to increased antioxidants and fewer cadmium residues; however, the inclusion criteria used by the authors was very broad, since it allowed the comparison of crops produced under very different parameters. Furthermore, antioxidant is a general classification encompassing very different molecules with different nutritional qualities and disparate effects on health. In addition, according to the data presented by Barańsky et al. (2014), protein and essential amino-acid content was low in organic compared to conventional food

(Mulet, 2014).

Another common belief is that additives or preservatives are not used in organic food production, whereas there is in fact a substantial list of allowed additives. In addition, the EU organic production regulation, point 25 , states:

\section{It is however considered} appropriate to limit the use of the EU-logo to products which contain only, or almost only, organic ingredients in order not to mislead consumers as to the organic nature of the entire product. It should therefore not be allowed to use it in the labelling of in-conversion products or processed foodstuffs of which less than $95 \%$ of its ingredients of agricultural origin are organic

(Council Regulation [EC] no. 834/2007) 
This means that a processed food item can be labelled as «organic» if $95 \%$ of its components are organic, even if the remaining $5 \%$ have not been produced according to the organic food regulation, and this needs not be indicated in the label.

If we focus on food security issues, organic food has proven to proportionally accumulate more alerts than conventional foods, including the dramatic Escherichia coli outbreak in France and Germany in June 2011 that resulted in 48 deaths (King et al., 2012). Another problem concerning food safety related to organic production is the high levels of dioxins, mainly in eggs, but also observed in other foods such as organic cheese. The presence of mycotoxins is also higher in organic corn than in conventional corn.

The main concern is the «yield gap»; that is, production drops due to decreased efficiency. Thus, in order to maintain food production according to organic standards, we must increase the area of agricultural soil, thence increasing the environmental impact and causing the emergence of the concomitant negative effect on biodiversity. A recent study showed that organic farming could be profitable and a general farming model in the future, but nowadays it accounts for less than $1 \%$ of global agriculture, and is strongly subsidized (Crowder \& Reganold, 2015).

Altogether the data points to a clear discrepancy between consumer perception of organic agriculture and what it really is. In fact, the term (organic, bio, or eco, depending on the country) has nothing to do with biology or agronomy; it is merely a legal term. The underlying problem is that, if we take a close look at regulations, we find that most of the rules are not based on scientific evidence and, what is more concerning, there are several important points based on superstition or pseudoscience, which can help to explain why organic production is not providing the consumers with what they are expecting.
WHAT IS THE EUROPEAN COUNCIL REGULATION BASED ON?

The fact that organic food production is failing in its objective of providing healthier food, or food whose production is more respectful to the environment, is mainly due to the fact that the European Council regulations on organic production are not based on any scientific foundation or relevant studies, but on a free interpretation of naturalist philosophy, often resorting to the appeal-tonature fallacy. According to this principle, the use of products of natural origin is allowed. The appeal to nature is an argument or rhetorical tactic which argues that a thing is good because it is «natural» or bad because it is «unnatural». This is an evident contradiction to our basic knowledge in chemistry, which states that the properties of any compound depend on its composition, not on its origin. For instance, the underlying logic that governs the regulation of pesticides is that only the ones that have a natural origin are authorized. For instance, copper is authorized in organic agriculture based on its natural origin, but it accumulates in the soil and can contaminate it or affect beneficial biodiversity such as earthworms. Another pesticide allowed in organic production is spinosad, a natural insecticide originating from the soil bacterium Saccharopolyspora spinosa, but it is toxic to nontarget pollinator species. This philosophy allows the use of antibiotics, greenhouses and ethylene. These aspects apparently contradict the philosophy of the regulation as stated in the foreword:

Organic production is an overall system of farm management and food production that combines best environmental practices, a high level of biodiversity, the preservation of natural resources, the application of high animal welfare standards and a production method in line with the preference of certain consumers for products produced using natural substances and processes

(Council Regulation [EC] No. 834/2007, foreword, point 1)

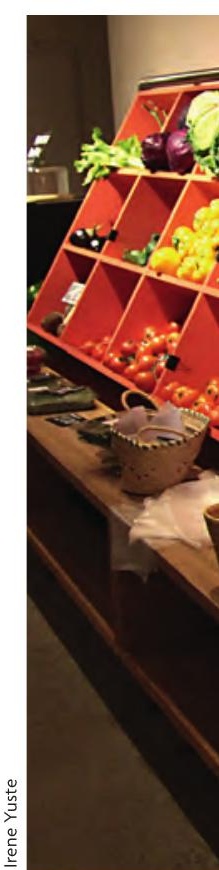


to organic wines. However, extreme weather conditions may provoke difficulties in certain wine-growing areas which make it necessary to use supplementary amounts of sulphites in the preparation of wine to achieve stability of the final product of that year. It should therefore be allowed to increase the maximum sulphur dioxide content when such conditions are met.

(Commission Implementing Regulation [EU] No. 203/2012, foreword, point 8)

So, in conclusion, this regulation allows the possibility to use the same amount of sulphites as in conventional wine. According to the same regulation, there are still some chemicals and products that can be used for organic wine-making, like potassium alginate (E-402, according to the European regulation) or oak chips, which are forbidden in the production of most quality wines. It is important to remark that organic wine may not be suitable for vegan consumers, due to the authorisation to use animal-derived products such as isinglass, egg white albumin, or casein. Again, in organic wine regulation there is a suggestion, but not an obligation, to use organic raw materials, which ultimately leads to less information for the consumer.

The affirmation that the regulation lacks a solid scientific base becomes clear when we compare the regulation of organic production in Europe with the equivalent regulation in the United States, since many differences exist. For instance, hydroponic cultures are allowed in the US, but not in Europe. In the US, the use of antibiotics is allowed in agriculture (Synthetic substances allowed for use in organic crop production, 2010), but not in livestock, exactly the opposite as in Europe, where one can use antibiotics for livestock (as long as they have not been produced from genetically modified organisms), but not in agriculture. Surprisingly, a similar «organic» label is awarded to food with very different methods of production or which have received very different inputs due to the disparity of the regulations.

\section{PSEUDOSCIENCE IN THE EUROPEAN REGULATIONS}

One of the main concerns about the regulation of organic production, which could indirectly account for its lack of effectiveness and the yield gap, is the fact that pseudoscience is explicitly present in some parts of it. For instance, chapter 2, article 12 (plant production rules), epigraph (c) of the Council Regulation (EC) No. 834/2007, states that «the use of biodynamic preparations is allowed». Biodynamic agriculture is a method apparently related to organic farming, but much older than the first European regulation, which dates from 1991. Biodynamic agriculture is based on a series of lectures given in 1924 by Rudolf Steiner, and focuses on spiritual and mystical perspectives based on the anthroposophy movement, which was also an invention by Steiner, originated as a segregation of the theosophy movement, an esoteric philosophy created by Helena Petrovna Blavatsky in 1875. Biodynamic practices are a compendium of superstition and beliefs with no scientific support or demonstration. The very few available studies comparing biodynamic production with organic or conventional production have failed to find any improvement at the nutritional quality level (Kirchmann, 1994). In fact, Steiner's assumptions were based on insights and inner visions from spiritualistic exercises and not on agricultural experiments or scientific evidence. This lack of scientific basis becomes clear when we read the descriptions of biodynamic preparations. For instance, number 503 consists in cutting chamomile flowers before 10 a.m., drying them and placing them into a fresh cow intestine, tying both sides, and burying them in the soil during autumn in an unglazed earthen jar, digging it up in early spring. Another example is biodynamic preparation number 505 , which consists in grinding oak bark into powder in autumn, placing it in a cow or sheep skull, and then burying it in a swamp or stream. Another practice includes the use of animal horns filled with manure (Klett, 2006). It is obvious that these practices are not related to science-based agriculture or food production, but to superstition. Another concern about the explicit inclusion of biodynamic preparations in the European regulation is the fact that the biodynamic certification depends mainly on a single company, Demeter, related to the theosophy movement.

Another case of pseudoscience that is explicitly mentioned in the organic regulation is homeopathy. Article 14 of the 2007 regulation reads:

[...] disease shall be treated immediately to avoid suffering of the animal; chemically synthesised allopathic veterinary medicinal products including

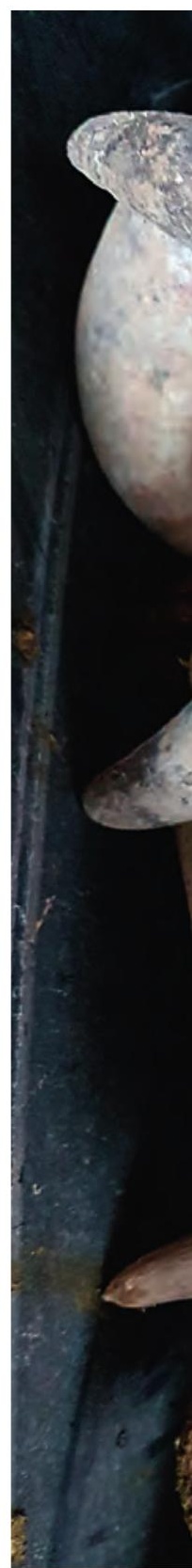




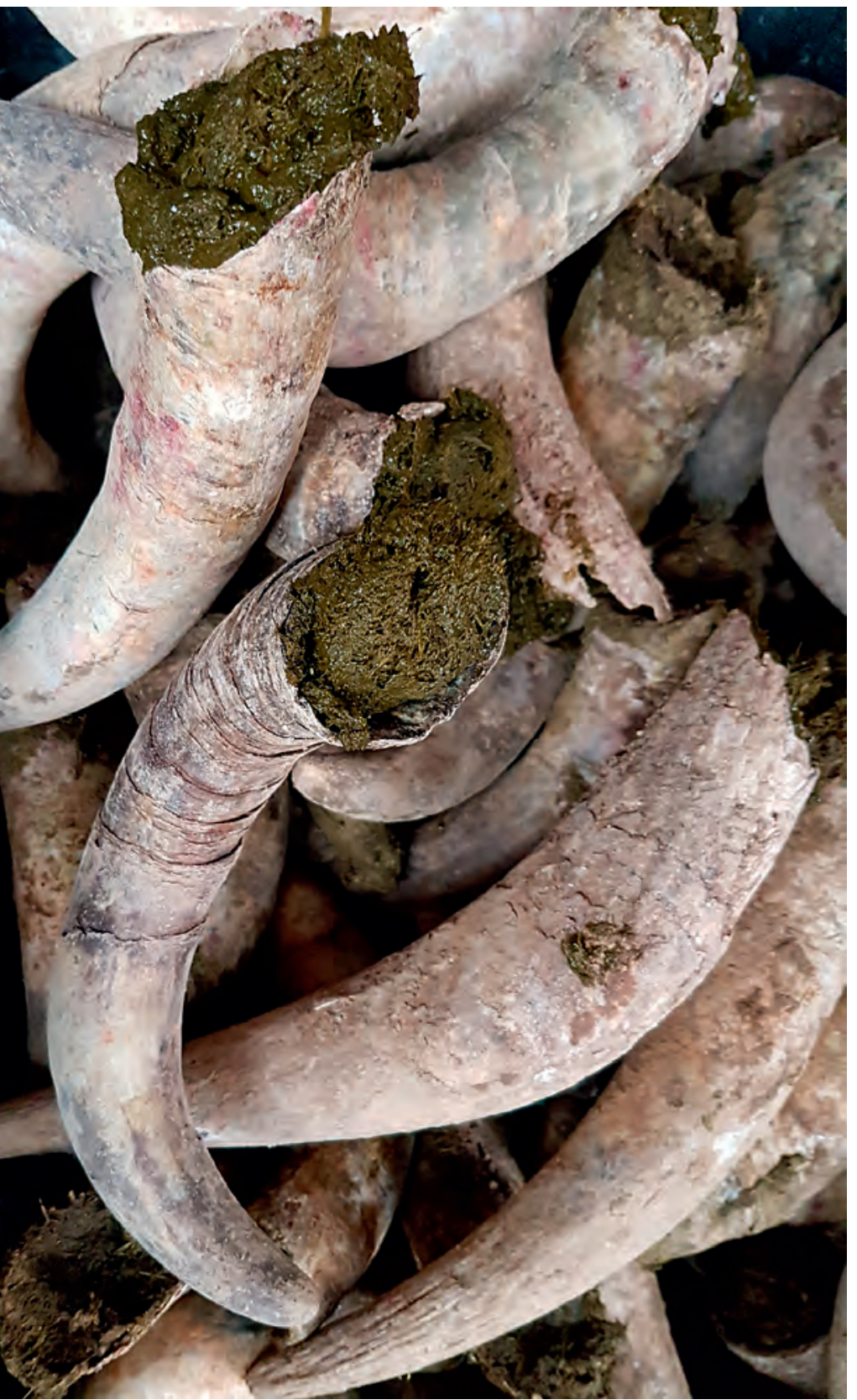

There are several important points in the European Union's pseudoscience-based regulations: for example, the use of biodynamic preparations, many of which have a strong superstitious component, is allowed. In the picture, cow horns stuffed with manure, a common practice in biodynamic agriculture.

«THE REJECTION OF TECHNOLOGY

IS ONE OF THE MAIN REASONS

EXPLAINING THE YIELD GAP BETWEEN CONVENTIONAL AND ORGANIC FARMING» antibiotics may be used where necessary and under strict conditions, when the use of phytotherapeutic, homeopathic and other products is inappropriate».

(Council Regulation [EC] No. 834/2007, article 14, epigraph [e], point second)

In addition, in the foreword to the Commission Implementing Regulation (EU) No. 354/2014 of 8 April 2014, point 9 indicates:

In the amended wording of Article 24(2) of Regulation (EC) No 889/2008, «homeopathic products» had erroneously been omitted. Since those products appeared in that provision before the amendment by Implementing Regulation (EU) No 505/2012, they need to be reinserted.

(Commission Implementing Regulation [EU]

No. 354/2014)

And point 1 of Article 2 determines that:

In Article 24, paragraph 2 is replaced by the following: «2. Phytotherapeutic and homeopathic products, trace elements and products listed in Section 1 of Annex V and in Section 3 of Annex VI shall be used in preference to chemically-synthesised allopathic veterinary treatment or antibiotics, provided that their therapeutic effect is effective for the species of animal, and the condition for which the treatment is intended».

The explicit mention of homeopathy in different regulations strengthens the idea of the lack of scientific evidence supporting organic agriculture. Homeopathy is based on the ideas of Samuel Hahnemann, a German doctor who died in 1843. In brief, the principles postulated by Hahnemann were that «like cures like» and that the more diluted a remedy, the more effective it is. Dilution in most homeopathic preparations usually continues well past the Avogadro number. Therefore, no molecule of the original preparation remains and the final product is plain water, which is usually sprayed on sugar pills. Homeopathy lacks biological plausibility and none of the axioms postulated by Hahnemann have been confirmed by science in two centuries. There are very few reports addressing any positive results from the use of homeopathy, and systematic reviews have failed to provide any evidence supporting the use of homeopathy, either in medicine, veterinary science nor farming. In fact, in two hundred years there is no single report in which a homeopathic treatment has proven efficient beyond the placebo, nor any medical, veterinary, or phytosanitary treatment in which homeopathy has substituted the conventional treatment or preparation with higher effectiveness (Hammarberg, 2001; Mathie \& Clausen, 2014), so there is no science-based reason for the 


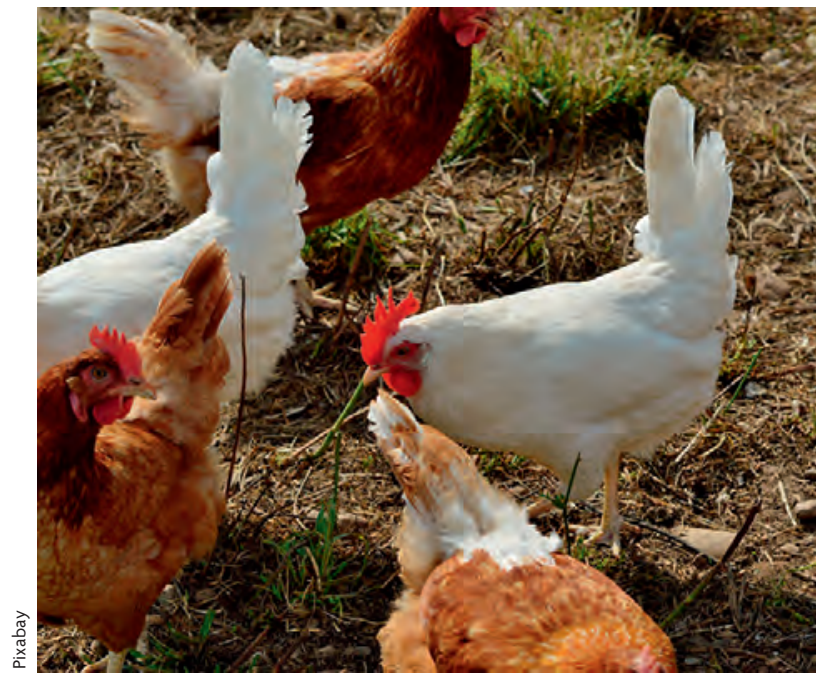

The European regulation on organic production prioritises the use of phytotherapeutic and homeopathic treatments to heal animal diseases over others such as antibiotics, provided that "their therapeutic effect is effective". At this time, homeopathy has not yet been shown to be more effective than a placebo. use in agriculture is still very limited, but several organizations related to organic farming, such as the British Soil Association, have already banned their use in organic production (Soil Association, 2009).

This evident rejection of technology is one of the main reasons explaining the yield gap between conventional and organic farming, and other problems such as food security. Organic regulations are intended for the method of production, not for the product itself, which means that the same seed or animal can be cultivated or raised as organic or conventional. That means that hybrids or new varieties obtained by induced mutagenesis using radioactivity or chemicals such as Ethyl methanesulfonate or colchicine are suitable for organic farming, but crops obtained by genetic engineering are not. This auto-limitation goes against some of the objectives and may explain the yield gap. In fact, it has been proposed that the use of new breeding techniques will substantially improve the performance of organic farming (Saher, Lindeman, \& Hursti, 2006). preferential use of homeopathy that the regulation indicates, since homeopathy cannot be considered an effective therapy.

\section{REJECTION OF TECHNOLOGY IN ORGANIC FARMING}

We have seen that the criteria for including or excluding agronomical practices in the regulations depends on concepts as difficult to define as «the true nature of organic production» (Commission Implementing Regulation [EU]

No. 203/2012). This principle allows artificial ripening, the use of greenhouses, but forbids hydroponic culture; allows non-specific insecticides such as spinosad, persistent fungicides such as copper and antibiotics, but forbids synthetic molecules even though they could have higher specificity or could break down into nontoxic molecules in a short time, avoiding accumulation in the soil or in the water as occurs with copper. This disparity is based on the natural or synthetic origin of the molecule and, again, on the appeal-to-nature fallacy. This criterion becomes clear when technologies such as genetic engineering are explicitly forbidden in the regulation, or the use of fertilizers if they have a synthetic origin (Council Regulation [EC] No. 834/2007). Other technologies like nanotechnology are not explicitly forbidden yet, given that their

\section{CONCLUSIONS}

It is difficult to believe that anyone would be against a model of agricultural production that is more sustainable and respectful to the environment. Most of the principles of organic farming, as stated in the foreword of the European regulation (Council Regulation [EC] No 834/2007) or by other entities such as IFOAM (International Federation of Organic Agriculture Movements, 2006) are the same ones most conventional farmers use in their production. The problem is that currently organic food represents a minor option aimed at highincome consumers. Representing less than $1 \%$ of the worldwide production and with a 20 to $50 \%$ yield gap compared to conventional production, it is difficult to believe that it will become a real option to feed the rising world population in the future. Concern arises when we study the regulations. Most of the methods proposed for reaching these objectives lack scientific evidence supporting the environmental benefit or the improvement in nutritional content of the final product. Some of the proposed methodologies, such as homeopathy or biodynamic agriculture, are based on pseudoscience. In addition, some of the banned methods or products could be effective for this purpose. A new regulation based not on their artificial 


\section{ORGANIC WINE}

es el resultado del trabajo de una tamilia de vificultores cuya filosofía está basada en una viticultura ecológica, respetuosa con el medio ambiente, minima intervención, siguiendo los biorritmos de la planta y sin utilización de herbicidas. uiva is the result of hard work of a family with a philosophy based on an organic viticulture, respectful with the environment, less intervention, following the biorhythms of the plant and organic fertilization.

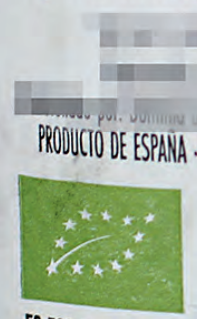

ES-ECO-026-VAS

Agricultura UE
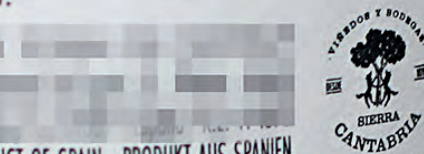

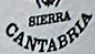
PRODUCT OF SPAIN - PRODUKT AUS SPANEN OBSAHUJE SIŘLČCTANY, INOEHOLDER SUEFHTER, BEVAI SUEFIETEX, CONTAWNS SULPHITES, SISALDAB SULFTIID, SISATIAA SUEVITEEA,

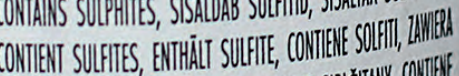

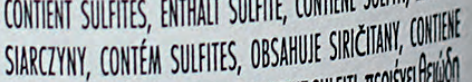

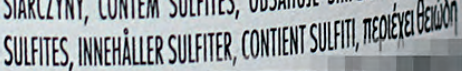

$750 \mathrm{ML}$ ALC. 13\% VOL.
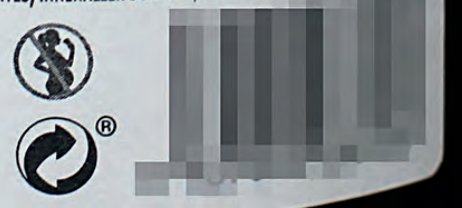

(n)

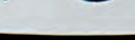

\section{d .}

